\title{
Remote-access hemithyroidectomy in a patient with papillary thyroid cancer after ipsilateral irradiation: a case report
}

\author{
Keiso Ho ${ }^{1,2}$, Yoshiyuki Saito ${ }^{1,3,4} \wedge$, Yoshifumi Ikeda ${ }^{5}$, Hiroshi Takami ${ }^{6}$, Toshiki Tokuda ${ }^{1}$, Ryohei Miyata ${ }^{1,7}$, \\ Masato Tomita ${ }^{1}$, Michio Sato ${ }^{1}$, Nobutoshi Ando ${ }^{1}$ \\ ${ }^{1}$ Department of Surgery, International Goodwill Hospital, Kanagawa, Japan; ${ }^{2}$ Department of Surgery, Ota Anniversary Hospital, Gunma, Japan; \\ ${ }^{3}$ Division of Thyroid and Parathyroid Endocrine Surgery, Department of Otolaryngology-Head and Neck Surgery, Massachusetts Eye and Ear \\ Infirmary, Harvard Medical School, Boston, MA, USA; ${ }^{4}$ Department of Surgery, Keio University School of Medicine, Keio University Hospital, \\ Tokyo, Japan; ${ }^{5}$ Department of Surgery, International University of Health and Welfare, Atami Hospital, Shizuoka, Japan; ${ }^{6}$ Department of Surgery, \\ Ito Hospital, Tokyo, Japan; ${ }^{7}$ Department of Surgery, Saiseikai Kurihashi Hospital, Saitama, Japan \\ Correspondence to: Dr. Yoshiyuki Saito. Department of Surgery, International Goodwill Hospital, 1-28-1 Nishigaoka, Izumi-ku, Yokohama, Kanagawa \\ 245-0006, Japan. Email: yoshiyuksaito@gmail.com.
}

\begin{abstract}
Remote-access thyroidectomy (RAT) is becoming a more frequently used approach that can avoid scars in the neck and provide better cosmetic results than open surgery. However, there has been no surgical indication for RAT in patients who have a history of cervical treatment (surgery or irradiation), and the use of RAT has been avoided in such patients. Here, we report a case in which a remote-access endoscopic hemithyroidectomy and central lymph node dissection by the anterior chest approach was successfully performed in a patient with papillary thyroid carcinoma (a 77-year-old Japanese male) after he had undergone ipsilateral cervical radiation therapy to parotid gland cancer (mucoepidermoid carcinoma) thirteen years earlier. Regarding trocar insertion, a 30-mm skin incision was made in the left anterior chest approx. $5 \mathrm{~cm}$ below the clavicle. Two $5-\mathrm{mm}$ trocars were inserted through the $30-\mathrm{mm}$ incision. We then insufflated with carbon dioxide to $6 \mathrm{mmHg}$. One additional $5-\mathrm{mm}$ trocar was placed cephalad to the 30-mm incision. When we performed this RAT, we detected no effect of the prior irradiation. To the best of our knowledge, this is the first report of RAT after irradiation. The cosmetic outcome of RAT is clearly superior, and the present case demonstrates that a RAT can be safely performed in carefully selected patients even after irradiation.
\end{abstract}

Keywords: Case report; endoscopic thyroidectomy; papillary thyroid carcinoma; remote-access; irradiation

Submitted Oct 26, 2021. Accepted for publication Jan 24, 2022.

doi: $10.21037 /$ gs-21-715

View this article at: https://dx.doi.org/10.21037/gs-21-715

\section{Introduction}

Remote-access thyroidectomy (RAT) was first reported in 2000 (1). Ohgami et al. approached the thyroid from a breast incision (an anterior chest approach) (2), and Ikeda et al. reported an axillary approach (3). These approaches provide better cosmetic results than open surgery, and the RAT procedure is now being performed more commonly. However, few institutions apply RAT to patients with a history of neck irradiation, as adhesions after irradiation are expected. We report an original case of a patient in whom an ipsilateral RAT was performed after neck irradiation. To the best of our knowledge, this is the first report to describe the implementation of a RAT after neck irradiation. We present the following case in accordance with the CARE reporting checklist (available at https://gs.amegroups.com/ article/view/10.21037/gs-21-715/rc).

^ ORCID: Keiso Ho, 0000-0002-5684-0557; Yoshiyuki Saito, 0000-0002-2462-6775. 


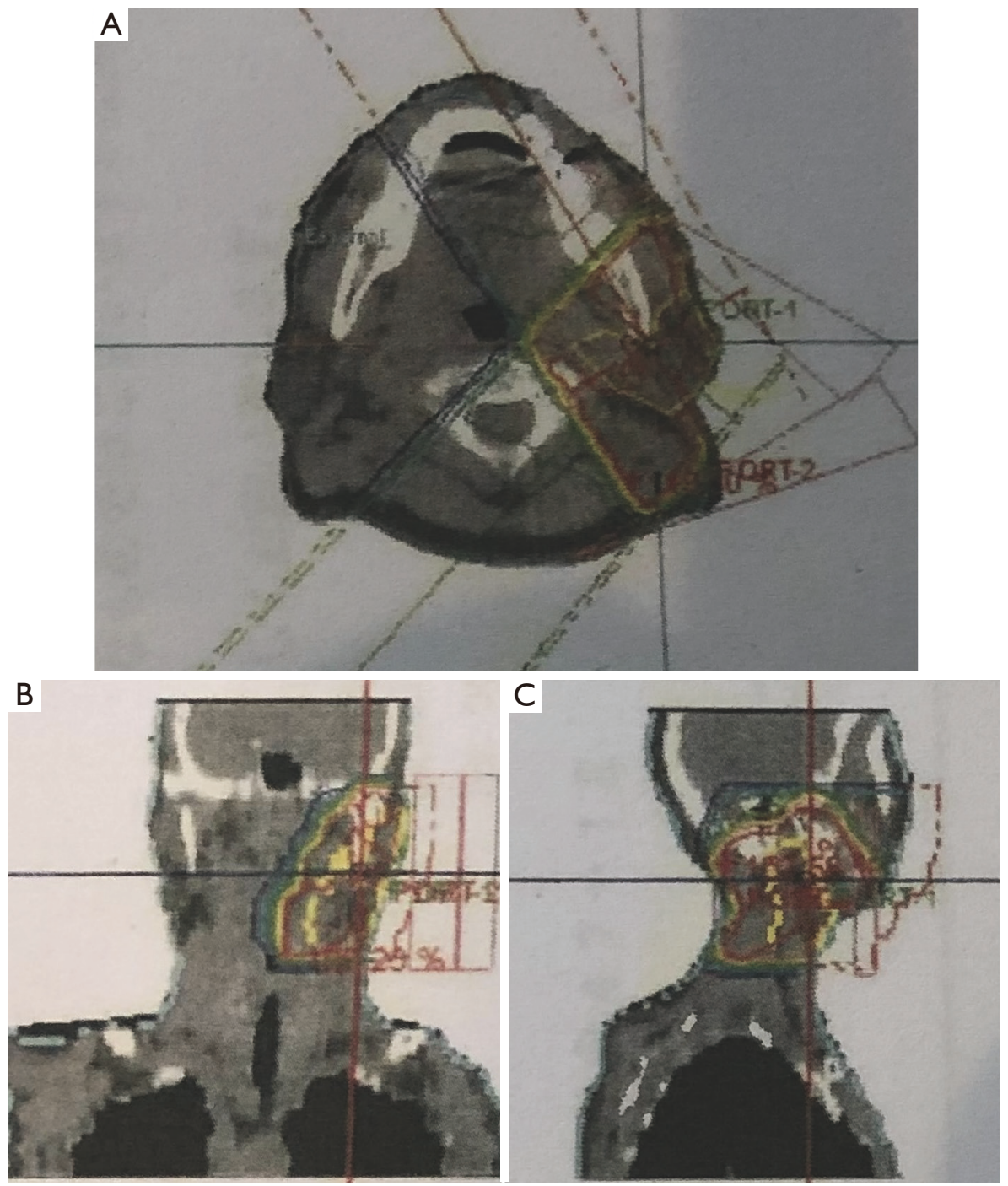

Figure 1 Original images of radiation treatment planning after the patient's surgery for parotid gland cancer 13 years prior to the present RAT. (A) Axial image; (B) coronal image; (C) sagittal image. RAT, remote-access thyroidectomy.

\section{Case presentation}

A 77-year-old Japanese man with a history of asthma and no remarkable family history underwent a computer tomography (CT) scan for the investigation of a chest disorder indicated by $\mathrm{X}$-ray findings at another medical examination, and the CT scan revealed a tumor in the left neck. Thirteen years earlier, he had been diagnosed with parotid gland cancer (mucoepidermoid carcinoma, pT1N0M0, pStageI) and was treated by surgery and irradiation with two angled fields [i.e., non-parallel opposed fields (50 Gy/25 fr)] (Figure 1). The irradiation area also included the cranial side of the left sternocleidomastoid muscle.
At the patient's present consultation, ultrasonography revealed a solid low-echoic tumor of the left thyroid $(20 \mathrm{~mm} \times 16 \mathrm{~mm} \times 15 \mathrm{~mm})$ (Figure 2), and the findings of fine-needle aspiration suggested papillary carcinoma (Bethesda System class V). Laboratory tests showed normal serum thyroid-stimulating hormone $(0.45 \mu \mathrm{U} / \mathrm{mL})$, normal free triiodothyronine $(1.34 \mathrm{pg} / \mathrm{mL})$, free thyroxine $(3.47 \mathrm{ng} / \mathrm{dL})$, and thyroglobulin $(0.70 \mathrm{ng} / \mathrm{mL})$, plus elevated anti-thyroglobulin antibody $(>4,000 \mathrm{IU} / \mathrm{mL})$. CT and magnetic resonance imaging (MRI) showed no lymph node swelling or distant metastasis (Figure 3).

We planned a left lobectomy and central lymph node 

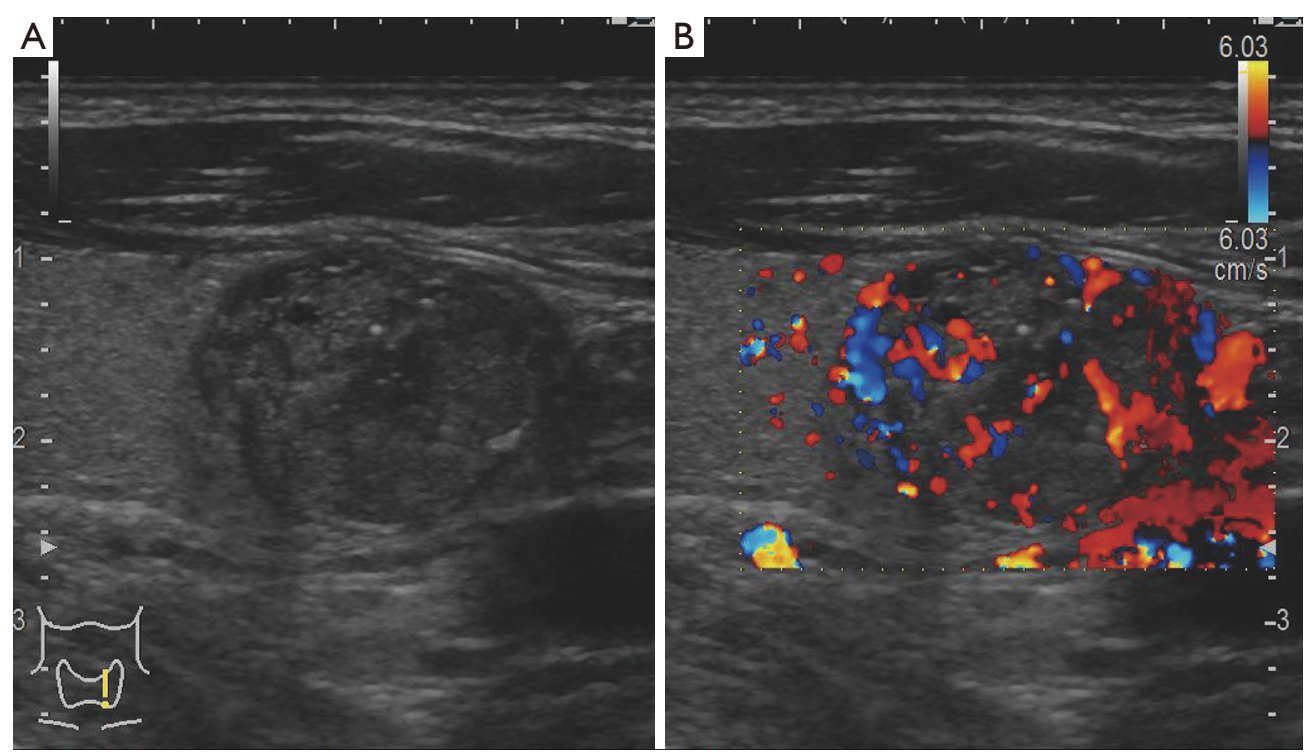

Figure 2 (A) Thyroid ultrasonography revealed a solid low-echoic tumor of the left thyroid (20 $\mathrm{mm} \times 16 \mathrm{~mm} \times 15 \mathrm{~mm})$. (B) Intrathyroidal blood flow signal image.
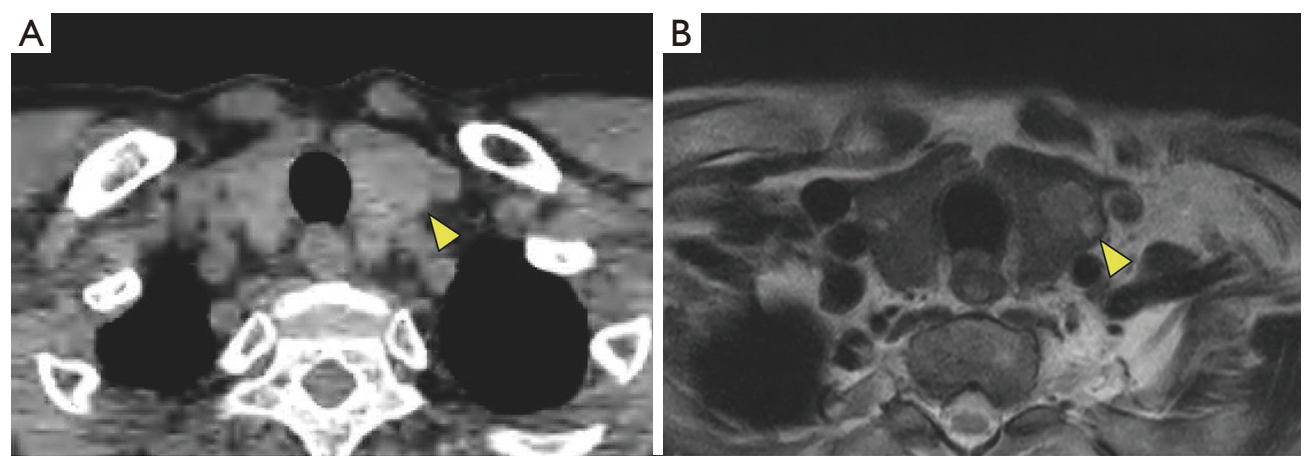

Figure 3 Preoperative imaging showing a 20-mm tumor (arrowhead) and no lymph node swelling. (A) Non-contrast CT scan; (B) magnetic resonance imaging.

dissection (cT1bN0M0, cStageI). Because the patient had a history of ipsilateral cervical surgery and irradiation, we explained the open neck approach, but the patient was motivated to avoid a cervical scar and requested endoscopic surgery. Given the patient's previous surgery and irradiation site, the irradiation effect was mainly in the area of the skin flap, and we speculated that if the skin flap dissection could be performed without any problem by methods other than the postauricular approach, the subsequent operations would have a lesser irradiation effect. We also expected that the scar in a patient at this advanced age (77 years) would be mild and acceptable due to loose skin tension. We thus selected an endoscopic hemithyroidectomy after fully explaining to the patient that it might be necessary to convert the procedure to open neck surgery due to effects of his previous cervical treatment.

A remote-access left hemithyroidectomy by the anterior chest approach was performed as described $(4,5)$. In brief, a $30-\mathrm{mm}$ skin incision was made in the left anterior chest approx. $5 \mathrm{~cm}$ below the clavicle. We conducted the flap dissection by detaching subcutaneous tissue toward the site at which the platysma muscle attaches to the pectoralis major muscle and then peeling off the inner layer of the sternocleidomastoid muscle. Although the irradiation area had included the cranial side of the left sternocleidomastoid muscle, we did not detect any effect of the previous 

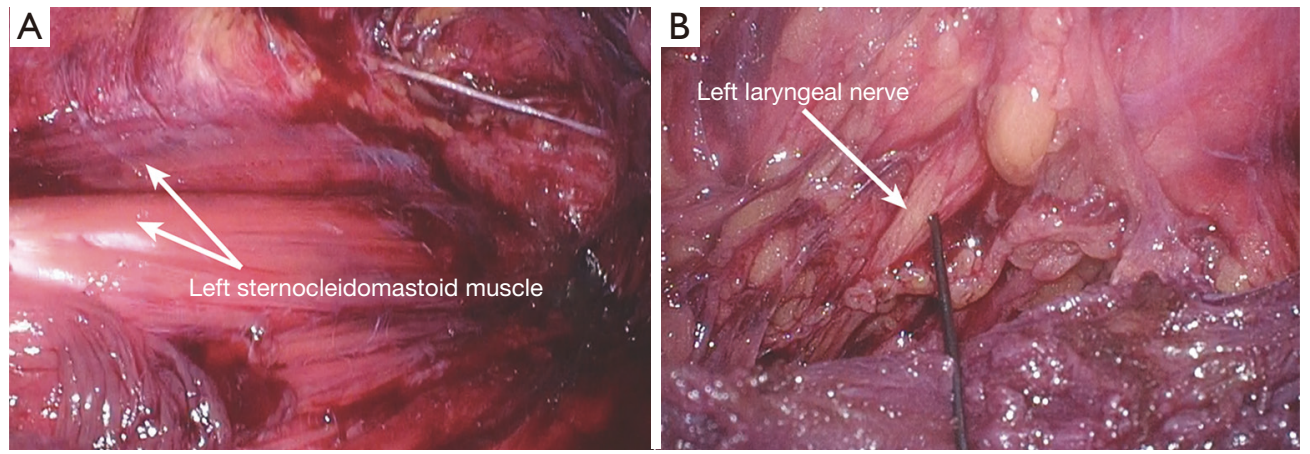

Figure 4 Intraoperative views. The patient's previous irradiation did not affect any aspect of the procedure. The right side is cranial. (A) After flap dissection. (B) Around the left recurrent laryngeal nerve.

irradiation during the skin flap dissection (Figure 4).

Two $5-\mathrm{mm}$ trocars were inserted through the $30-\mathrm{mm}$ incision. We then insufflated with carbon dioxide to $6 \mathrm{mmHg}$. One additional 5 -mm trocar was placed cephalad to the $30-\mathrm{mm}$ incision. No effect of the prior irradiation was detected around the recurrent laryngeal nerve. We also performed central lymph node dissection and confirmed the preservation of the recurrent laryngeal nerve by intraoperative nerve monitoring. The operation time was $287 \mathrm{~min}$, and there was only minimal intraoperative bleeding $(<5 \mathrm{~mL})$. The pathological examination's result was papillary thyroid carcinoma (pT1bN0M0, pStageI), and there were no complications after surgery. Over a year has passed since the operation, without recurrence.

All procedures performed in this study were in accordance with the ethical standards of the institutional and/or national research committee(s) and with the Helsinki Declaration (as revised in 2013). Written informed consent was obtained from the patient for publication of this case report and accompanying images. A copy of the written consent is available for review by the editorial office of this journal.

\section{Discussion}

According to the American Thyroid Association (ATA) statement on RAT (6), absolute contraindications for RAT include evidence of thyroid cancer with extrathyroidal extension or lymph node involvement, Graves' disease, substernal extension, and previous neck surgery. Ipsilateral reoperation after thyroid surgery is thought to pose a high risk of recurrent laryngeal nerve paralysis (RLNP) (7). A review of 115 cases of reoperation of thyroid surgery (mainly completion total thyroidectomy) revealed that the complication rate of permanent RLNP was $1.7 \%$ (8). It can thus be concluded that if the effects of a previous surgery did not reach the recurrent laryngeal nerve, the risk of complications due to reoperation is low, and in the present case the risk of RLNP was also considered to be low. Several cases in which RAT was performed after an ipsilateral thyroidectomy were recently reported $(5,9,10)$, and in all of these reports, the RATs were safely performed without any complications.

Irradiation is considered to cause fibrosis of soft tissue, leading to high-risk surgery (11). However, several studies of open neck surgery after ipsilateral irradiation demonstrated that the surgery was safely performed, and the complication rates were sufficiently low: $0-1.5 \%$ for RLNP, $0-2.8 \%$ for hypoparathyroidism, and $0-1.5 \%$ for postoperative hematoma $(5,12-14)$. Kikuchi et al. reviewed 171 cases and reported that there was no significant difference in the incidence of complications between the group of patients with an irradiation history and the non-irradiation history group (15). They concluded that experienced surgeons could safely perform a thyroidectomy even in patients with a history of irradiation. However, to the best of our knowledge, there is no published report of RAT after ipsilateral irradiation.

Surgery after irradiation is one of the standard treatments for rectal cancer and esophageal cancer. Many laparoscopic surgeries have been conducted for patients with these cancers, and it has been demonstrated that the complication rate is not increased in the patients with an irradiation history $(16,17)$. In our patient's case as well, the surgery was performed without complications. Surgery after irradiation is one of the standard treatments for rectal cancer and esophageal 
cancer. Many laparoscopic surgeries have been conducted for patients with these cancers, and it has been demonstrated that the complication rate is not increased in patients with an irradiation history $(16,17)$. In our patient's case as well, the surgery was performed without complications.

Although RAT provides excellent cosmetic results, it can cause both more tissue damage and the need for a longer operation time due to the resulting greater dissection plane compared to conventional surgery. A RAT should thus be performed only in carefully selected patients. Moreover, the contraindications for RAT are not always absolute. We thus conclude that a RAT can be safely performed by wellexperienced surgeons in cases with the contraindications such as previous cervical treatment (surgery and/or irradiation).

\section{Acknowledgments}

Funding: None.

\section{Footnote}

Reporting Checklist: The authors have completed the CARE reporting checklist. Available at https://gs.amegroups.com/ article/view/10.21037/gs-21-715/rc

Peer Review File: Available at https://gs.amegroups.com/ article/view/10.21037/gs-21-715/prf

Conflicts of Interest: All authors have completed the ICMJE uniform disclosure form (available at https://gs.amegroups. com/article/view/10.21037/gs-21-715/coif). The authors have no conflicts of interest to declare.

Ethical Statement: The authors are accountable for all aspects of the work in ensuring that questions related to the accuracy or integrity of any part of the work are appropriately investigated and resolved. All procedures performed in this study were in accordance with the ethical standards of the institutional and/or national research committee(s) and with the Helsinki Declaration (as revised in 2013). Written informed consent was obtained from the patient for publication of this case report and accompanying images. A copy of the written consent is available for review by the editorial office of this journal.

Open Access Statement: This is an Open Access article distributed in accordance with the Creative Commons
Attribution-NonCommercial-NoDerivs 4.0 International License (CC BY-NC-ND 4.0), which permits the noncommercial replication and distribution of the article with the strict proviso that no changes or edits are made and the original work is properly cited (including links to both the formal publication through the relevant DOI and the license). See: https://creativecommons.org/licenses/by-nc-nd/4.0/.

\section{References}

1. Russell JO, Noureldine SI, Al Khadem MG, et al. Minimally invasive and remote-access thyroid surgery in the era of the 2015 American Thyroid Association guidelines. Laryngoscope Investig Otolaryngol 2016;1:175-9.

2. Ohgami M, Ishii S, Arisawa Y, et al. Scarless endoscopic thyroidectomy: breast approach for better cosmesis. Surg Laparosc Endosc Percutan Tech 2000;10:1-4.

3. Ikeda Y, Takami H, Sasaki Y, et al. Endoscopic neck surgery by the axillary approach. J Am Coll Surg 2000;191:336-40.

4. Saito Y, Ikeda Y, Katoh H, et al. Is total endoscopic parathyroidectomy an acceptable treatment for patients with primary hyperparathyroidism due to a presumed solitary adenoma?-comparison of minimally invasive total endoscopic parathyroidectomy and open minimally invasive parathyroidectomy. Gland Surg 2021;10:83-9.

5. Nakao A, Saito Y, Ikeda Y, et al. Total endoscopic thyroidectomy after open neck biopsy of the follicular lymphoma of the thyroid gland. Asian J Endosc Surg 2021;14:275-8.

6. Berber E, Bernet V, Fahey TJ 3rd, et al. American Thyroid Association Statement on Remote-Access Thyroid Surgery. Thyroid 2016;26:331-7.

7. Landerholm K, Wasner AM, Järhult J. Incidence and risk factors for injuries to the recurrent laryngeal nerve during neck surgery in the moderate-volume setting. Langenbecks Arch Surg 2014;399:509-15.

8. Chao TC, Jeng LB, Lin JD, et al. Reoperative thyroid surgery. World J Surg 1997;21:644-7.

9. Razavi CR, Tufano RP, Russell JO. Completion thyroidectomy via the transoral endoscopic vestibular approach. Gland Surg 2018;7:S77-9.

10. Park JO, Anuwong A, Kim MR, et al. Transoral endoscopic thyroid surgery in a Korean population. Surg Endosc 2019;33:2104-13.

11. Delbridge L, Sutherland J, Somerville H, et al. Thyroid surgery and anaesthesia following head and neck 
irradiation for childhood malignancy. Aust N Z J Surg 2000;70:490-2.

12. Kaplan EL. Operation of the irradiated gland for possible thyroid carcinoma: Criteria, technique and results. In: DeGroot LJ, Frohman LA, Kaplan EL, et al. editors. Radiation-Associated Thyroid Carcinoma. New York: Grune \& Stratton, Inc., 1977:371-82.

13. Paloyan E. Operation of the irradiated gland for possible thyroid carcinoma: Criteria, technique and results. In: DeGroot LJ, Frohman LA, Kaplan EL, et al. New York: Grune \& Stratton, Inc., 1977:383-94.

14. Swelstad J, Scanlon EF, Murphy ED, et al. Thyroid disease following irradiation for benign conditions. Arch Surg 1977;112:380-3.

Cite this article as: Ho K, Saito Y, Ikeda Y, Takami H, Tokuda T, Miyata R, Tomita M, Sato M, Ando N. Remoteaccess hemithyroidectomy in a patient with papillary thyroid cancer after ipsilateral irradiation: a case report. Gland Surg 2022;11(3):622-627. doi: 10.21037/gs-21-715
15. Kikuchi S, Perrier ND, Cheah WK, et al. Complication of thyroidectomy in patients with radiation-induced thyroid neoplasms. Arch Surg 2004;139:1185-8.

16. Kang SB, Park JW, Jeong SY, et al. Open versus laparoscopic surgery for mid or low rectal cancer after neoadjuvant chemoradiotherapy (COREAN trial): shortterm outcomes of an open-label randomised controlled trial. Lancet Oncol 2010;11:637-45.

17. Koyanagi K, Kato K, Ito $\mathrm{Y}$, et al. Impact of preoperative therapy for locally advanced thoracic esophageal cancer on the risk of perioperative complications: Results from multicenter phase III trial JCOG 1109. J Clin Oncol 2021;39:162. 